\title{
Teoria Axiológica de Comunhão: a construção social de recursos constitutivos da gestão de empresas de Economia de Comunhão
}

\author{
Cláudia Herrero Martins Menegassı \\ Centro Universitário Cesumar / Programa de Pós-Graduação em GeStão do CONHECimento nas OrganizaçÕes \\ (PPGGCO/UNICESUMAR), MARINGÁ- PR, BRASIL \\ Bruno Henrique Rocha Fernandes \\ Universidade Positivo / Programa de Mestrado e Doutorado em Administração (PMDA/UP), CUritiba- PR, BrasiL
}

\begin{abstract}
Resumo
Esta pesquisa visou a elaborar uma Grounded Theory para explicar como são socialmente construídos os recursos que constituem a gestão de empresas de Economia de Comunhão (EdC). Para abordar o problema, foi usada a Resource-Based View (RBV) como mecanismo de sensibilização teórica e foi desenvolvida uma Grounded Theory. A coleta de dados ocorreu por meio de entrevistas e análise documental. Para a análise foram realizadas codificações aberta, axial e seletiva e amostragens teóricas, em processo concomitante e recursivo. Como resultado, emergiram sete categorias, que, relacionadas entre si e com a categoria central, deram origem à Teoria Axiológica de Comunhão, propondo que a influência axiológica dos empresários e a cultura de comunhão são os elementos determinantes para a construção social dos recursos que constituem a gestão de empresas baseada na EdC.
\end{abstract}

Palavras-chave: Economia de Comunhão. Grounded Theory. Teoria Axiológica de Comunhão.

The Axiological Theory of Communion: the social construction of the resources that constitute business management in an Economy of Communion

\begin{abstract}
This research aimed to devise a Grounded Theory to explain how the resources constituting the Economy of Communion (EoC) business management are socially constructed. To address the issue, the Resource-Based View (RBV) was used as a theoretical awareness-raising mechanism and a Grounded Theory was devised. Data collection took place through interviews and documentary analysis. For the analysis, open, axial, and selective coding, as well as theoretical samplings, were performed in a simultaneous and recursive process. As a result, seven categories emerged, which, related to each other and having a central category, generated the Axiological Theory of Communion, claiming that entrepreneurs' axiological influence and the culture of communion are the key elements for the social construction of resources that constitute the management of businesses based on the EoC.
\end{abstract}

Keywords: Economy of Communion. Grounded Theory. Axiological Theory of Communion.

Teoría Axiológica de Comunión: la construcción social de recursos constitutivos de la gestión de empresas de Economía de Comunión

\section{Resumen}

Esta investigación tuvo como objetivo elaborar una Grounded Theory para explicar la forma en que se construyen socialmente los recursos que constituyen la gestión de las empresas de Economía de Comunión (EdC). Para abordar la cuestión, la Resource-Based View (RBV) fue utilizada como mecanismo de sensibilización teórica y una Grounded Theory fue ideada. Los datos fueron recolectados a través de entrevistas y análisis de documentos. Para el análisis, se realizaron codificación abierta, axial y selectiva, así como muestreos teóricas, en un proceso simultáneo y recursivo. Como resultado, siete categorías emergieron, que, relacionados entre sí y con la categoría central, originaron la Teoría Axiológica de Comunión, proponiendo que la influencia axiológica de los empresarios y de la cultura de comunión son los elementos clave para la construcción social de los recursos que constituyen la gestión de las empresas sobre la base de la EdC.

Palabras clave: Economía de Comunión. Grounded Theory. Teoría Axiológica de Comunión. 


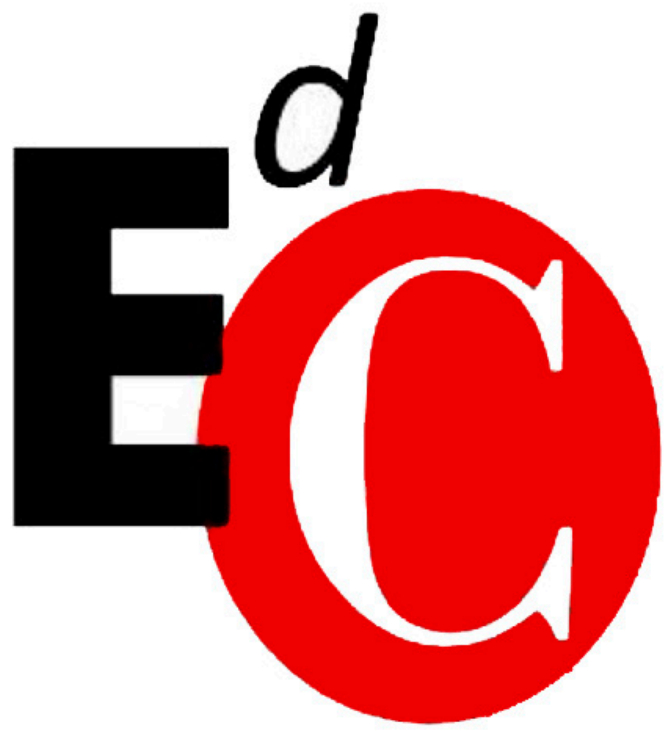

\section{INTRODUÇÃO}

A área substantiva que motivou esta pesquisa é composta pelas empresas que adotam uma abordagem de gestão denominada Economia de Comunhão (EdC). A EdC nasceu de uma proposta de Chiara Lubich, em 1991, com poucas diretrizes iniciais - relacionadas à divisão do lucro em três partes: para o reinvestimento na empresa; para pessoas com necessidades econômicas; e para a formação de pessoas para a cultura de comunhão. Daí em diante a EdC foi adotada por empresários que se identificaram com o projeto.

Outros princípios foram acrescentados à proposta ao longo do desenvolvimento da EdC, relacionados ao meio ambiente, ao relacionamento com os stakeholders e a questões éticas, entre outros, o que configurou a EdC como uma abordagem de gestão e não somente como uma proposta de destinação diferenciada do lucro.

Há diversas abordagens de gestão no ambiente empresarial com diferentes propostas e graus de estruturação. A estrutura, ou mesmo a falta dessa, pode ser algo que as caracterize e que deixam maior ou menor liberdade para interpretações por parte dos empresários que decidem adotar alguma dessas abordagens de gestão em suas empresas.

A Economia de Comunhão tem certa estrutura formal de apoio e preserva a liberdade dos empresários de adequá-la às suas empresas. Desse modo, embora haja algumas linhas gerais para a gestão de EdC, essa abordagem de gestão não é dada, mas socialmente construída, e isso se dá com base em escolhas do empresário e de sua influência na construção social dos recursos específicos necessários para que se objetive em sua empresa. Não obstante essa liberdade de atuação, a EdC mantém uma identidade comum, mesmo entre empresas de diferentes atividades, setores, regiões e países.

Em se tratando de recursos, a Resource-Based View (RBV) se destaca por ser uma teoria de estratégia voltada à análise dos recursos internos das empresas, desde sua concepção, suas características até a pesquisa do impacto dos recursos na gestão estratégica das empresas. É uma teoria ampla sobre recursos no campo da estratégia e contribui para a compreensão dos recursos e de suas combinações que conduzem à finalidade da empresa - que, para essa teoria, é a vantagem competitiva sustentável. Todavia, apesar de ser uma teoria de referência no tocante aos recursos, a RBV não aborda satisfatoriamente a construção social dos recursos.

\footnotetext{
* Fonte da imagem: Associação Nacional por uma Economia de Comunhão.
} 
A razão disso são os pressupostos ontológicos e epistemológicos assumidos por essa teoria, oriundos da economia, segundo os quais a realidade é dada e não construída e, assim, concebe os recursos como adquiridos ou herdados, sem considerar sua construção social e a abordagem de gestão que os contém. A RBV com suas bases funcionalistas - que pressupõem a explicação racional para os fenômenos sociais e a busca por soluções práticas para problemas práticos (BURRELL e MORGAN, 1979) - limita seu alcance ao pragmatismo que nem sempre fornece uma ampla explicação acerca dos fenômenos. Desse modo, a RBV não tem alcance para responder os questionamentos levantados nesta pesquisa, embora essa teoria propicie importantes insights no que se refere a recursos e tenha muito a contribuir como mecanismo de sensibilização teórica.

Ao conceber a empresa como um espaço social oriundo da concepção de vida e de gestão do proprietário, as definições das estratégias do negócio e a abordagem de gestão adotada na empresa dependerão desse ator social e de suas prioridades também em termos de valores, escolhas e ações. Essa concepção pode propiciar outras finalidades à empresa que redefinem sua abordagem de gestão, como acontece naquelas que adotam a Economia de Comunhão, e cuja centralidade da atividade produtiva está direcionada ao ser humano e ao bem comum (PINHEIRO, 2000).

Sendo assim, é fundamental considerar o papel do empresário como ator social e suas interpretações para compreender a construção social dos recursos que constituem a abordagem de gestão de Economia de Comunhão e isso é possível por meio de uma pesquisa de base construtivista.

Desse modo, o objetivo desta pesquisa é elaborar uma teoria substantiva fundamentada nos dados que explique como são socialmente construídos os recursos que constituem a gestão de empresas baseada na Economia de Comunhão. O objetivo é responder ao seguinte problema de pesquisa: como os recursos que constituem a gestão de empresas baseada na Economia de Comunhão são socialmente construídos?

\section{DEFINIÇÃO DA ÁREA SUBSTANTIVA DE PESQUISA}

A área substantiva desta pesquisa são as empresas de Economia de Comunhão (EdC). A Economia de Comunhão foi um projeto lançado por Chiara Lubich, italiana, fundadora do Movimento dos Focolares em 29 de maio de 1991, por ocasião de uma visita sua ao Brasil. O Movimento dos Focolares teve início em 1943 em Trento, no norte da Itália, durante a Segunda Guerra Mundial. Difundiu-se ao longo das décadas pelos cinco continentes, estando atualmente em 182 países, com cerca de 2 milhões de aderentes. No Brasil, o Movimento teve início em 1959; está presente em todos os estados e conta com cerca de 280 mil membros (QUEM SOMOS, 2012).

A espiritualidade do Movimento dos Focolares foi definida como coletiva. A unidade é o princípio que agrega os demais princípios do Movimento: a caridade, o amor ao próximo, o amor recíproco, a vivência do Evangelho e a cultura da partilha (ESTATUTOS, 2007). Apesar de ter sido criado tendo por base princípios católicos, o Movimento atua em prol do diálogo ecumênico, inter-religioso e com pessoas sem um referencial necessariamente de fé. As iniciativas desenvolvidas pelo Movimento estão em campos como a cultura, a política, a economia, o direito, a educação, a saúde, a comunicação, a arte e a ciência (QUEM SOMOS, 2012). A Economia de Comunhão é uma dessas iniciativas. Desse Movimento a EdC herdou seus princípios centrais.

Na 55a Sessão da Comissão para o Desenvolvimento Social, promovida em 2012 pela Organização das Nações Unidas (ONU), foi apresentada uma ampla definição da Economia de Comunhão, que demonstra sua proposta, princípios e motivações:

A Economia de Comunhão propõe que as economias e as empresas deveriam adotar, juntamente com os princípios de liberdade e igualdade, o princípio da fraternidade. Ao fazer isso, a atividade empresarial e econômica pode contribuir para a realização de cada pessoa humana, respondendo ao nosso profundo desejo de felicidade e um senso de propósito (STATEMENT, 2012, p. 3).

De modo mais específico, a Economia de Comunhão é definida como "um movimento que envolve empresários, empresas, associações, instituições econômicas, mas também trabalhadores, gestores, consumidores, poupadores, pesquisadores, operadores econômicos, pobres, cidadãos, famílias" (CARTEIRA, 2012) e tem diversas dimensões e, em sua essência, são estes seus objetivos centrais: 
O seu objetivo é, à luz do Carisma da Unidade, contribuir ao nascimento de empresas fraternas que têm a missão de erradicar a miséria e a injustiça social, para contribuir a edificar um sistema econômico e uma sociedade humana de comunhão.

Visa favorecer a geração do agir econômico, seja no momento da elaboração das estratégias, seja no momento da sua concretização, com atenção à promoção integral da pessoa e da sociedade, através de ações e comportamentos inspirados na fraternidade (LINHAS, 2007).

A Economia de Comunhão opera para estimular a passagem da economia e da sociedade inteira da cultura do ter à cultura do dar e da fraternidade universal, e se propõe à livre adesão do mundo econômico nas suas várias formas (LINHAS, 2007).

A chamada cultura da partilha é um dos princípios básicos da EdC. O projeto prevê que os empresários destinem livremente parte dos lucros obtidos em suas empresas a três finalidades: ao reinvestimento na própria empresa; à ajuda a pessoas necessitadas; e ao desenvolvimento de estruturas que visem à formação de pessoas voltadas a essa cultura (LUBICH, 2002). Os demais princípios do Movimento dos Focolares foram incorporados à proposta da EdC, o que originou o delineamento da abordagem de gestão de Economia de Comunhão, que abarca diversos aspectos de gestão.

Para a prática da Economia de Comunhão, há uma estrutura funcional que organiza os processos envolvidos, representa a EdC e serve de apoio para empresas e desenvolvimento dos projetos, como as Associações (internacional e nacional), as Comissões (central e locais), uma organização não governamental (ONG), além dos Polos Empresariais e das empresas de EdC.

Embora não haja uma padronização rigorosa em termos de gestão de Economia de Comunhão nas empresas, há algo em comum entre elas: a vontade dos empresários em atuar segundo os princípios da Economia de Comunhão e de contribuir para uma sociedade mais fraterna e igualitária - não há nenhum incentivo fiscal ou de publicidade associados à adesão. É isso que caracteriza a área substantiva desta pesquisa.

No mundo há 840 empresas de EdC e no Brasil, 167, segundo dados de 2011 (CRIVELLI, 2011). O lucro doado por essas empresas para pessoas com necessidades e para a formação de pessoas no ano de 2011 foi de $€ 966.744,50$ (BRUNI, 2012).

\section{SENSIBILIZAÇÃO TEÓRICA}

Nesta pesquisa foi feita uma Grounded Theory. Essa metodologia pressupõe uma lógica abdutiva, sem resgates conceituais de uma literatura específica com a finalidade de referenciar a pesquisa, mas um posicionamento analítico diante das teorias existentes, para nelas descobrir lacunas que possam ser revistas "por uma visão original construída a partir do ponto de vista dos envolvidos" (BANDEIRA-DE-MELLO e CUNHA, 2007, p. 260).

Por ser uma das teorias que explicam de forma mais abrangente o que se refere aos recursos internos das empresas, a ResourceBased View (RBV) contribuiu para a pesquisa, oferecendo insights ao trabalho de teorização acerca de recursos. Todavia, os pressupostos ontológicos e epistemológicos da Grounded Theory são de base construtivista, distintos daqueles da RBV, que assume como ontologia a realidade dada e é regida pelo paradigma funcionalista, que pressupõe a explicação racional dos fenômenos sociais e a busca por soluções práticas para problemas práticos (BURRELL e MORGAN, 1979).

Desse modo, a teoria substantiva construída com base nesta pesquisa não tem relação direta com a RBV, mas a considerou um importante mecanismo de sensibilização teórica, tendo sido analisados sua origem (PENROSE, 1959; RUBIN, 1973; WERNERFELT, 1984), trajetória teórica (DIERICKS e COOL, 1989; BARNEY, 1991; GRANT, 1991; MONTGOMERY, 1995; FOSS, 1997; ACEDO, BARROSO e GALAN, 2006; BARNEY, KETCHEN JR. e WRIGHT, 2011), pontos críticos (REED e DEFILLIPPI, 1990; PORTER, 1991; CONNER, 1991; AMIT e SCHOEMAKER, 1993; RUMELT, 1995; MONTGOMERY, 1995; PRIEM e BUTLER, 2001a; 2001b) e abertura a outros desdobramentos da RBV (WERNERFELT, 1995; BRYSON, ACKERMANN e EDEN, 2007).

A RBV tem-se expandido nos estudos das organizações, constituindo uma das principais teorias no campo da estratégia, onde é a principal corrente teórica que trata dos recursos internos das empresas. 
A primeira vez que o termo Resource-Based View apareceu na literatura foi em Wernerfelt (1984), autor que remete a origem da RBV aos trabalhos seminais de Penrose (1959) e Rubin (1973), valendo-se também do conceito de recurso desenvolvido por Caves (1980, p. 65, tradução nossa):

A firma se baseia em relações contratuais que unem e coordenam vários ativos ou fatores fixos, alguns físicos, outros que consistem em habilidades humanas, conhecimentos e experiência - alguns deles compartilhados coletivamente pela hierarquia administrativa. Esses fatores são considerados por estarem vinculados de modo semipermanente à empresa pelos custos de contratação e, talvez, pelas imperfeições de mercado.

Wernerfelt (1984) aponta que, nessa perspectiva, as empresas são caracterizadas por uma combinação de recursos e não pelo posicionamento de seus produtos no mercado, e direciona a sua análise ao escopo da vantagem competitiva.

Foss (1997) tenta simplificar a RBV - por ele chamada de Resource-Based Perspective ou RBP - como algo diretamente relacionado à vantagem competitiva. Foss (1997, p. 4, tradução nossa) afirma que a RBV tem por base duas generalizações empíricas: "[1] há diferenças sistemáticas entre as firmas à medida que elas controlam os recursos necessários para a implementação de estratégias; [2] essas diferenças são relativamente estáveis". Essas duas generalizações, combinadas com duas outras suposições, formam a base da RBV. As suposições são: "[1] diferenças nas alocações de recursos das empresas causam diferença de desempenho; [2] as empresas procuram aumentar (se não necessariamente maximizar) seu desempenho econômico" (FOSS, 1997, p. 4, tradução nossa). Desse modo, o autor destaca que o objetivo geral da RBV é "explicar a criação, a manutenção e a renovação da vantagem competitiva em termos do aspecto dos recursos das empresas" (FOSS, 1997, p. 4, tradução nossa).

Várias são as críticas feitas por autores à RBV. A primeira é atribuída à sua própria origem: a economia e, mais especificamente, a microeconomia. A esse respeito Rumelt (1995) aponta que, apesar do desenvolvimento rico da microeconomia e de sua influência no campo da estratégia empresarial - cujos primeiros estudos seguiram seus pressupostos - há a necessidade de cautela no uso de lógicas econômicas dentro do campo. Segundo Rumelt (1995, p. 103, tradução nossa), "há uma série de pressupostos errôneos que os pesquisadores economicamente orientados continuam a tomar emprestado da economia" e que nem sempre são adequados ao estudo de temas do management.

Outros autores - como Demsetz (1973), Mancke (1974), Barney (1986) e Collins e Montgomery (1995) - consideraram a ambiguidade causal uma das principais dificuldades de se compreender a vantagem competitiva sustentável pela RBV. O conceito de ambiguidade causal refere-se à impossibilidade, sobretudo dos concorrentes, em distinguir qual recurso ou qual combinação exata de recursos levou determinada empresa a obter vantagem competitiva, dada a complexidade da combinação dos recursos (DIERICKS e COOL, 1989). Se, por um lado, isso pode ser concebido como ponto crítico da teoria, por outro, os autores apontam que a ambiguidade causal pode significar uma proteção à vantagem competitiva da empresa, uma vez que consiste em uma barreira à imitação (LIPPMAN e RUMELT, 1982; REED e DEFILLIPPI, 1990).

É importante destacar que muito ainda se teria a dizer a respeito da RBV, mas isso poderia desviar o foco deste trabalho, em que essa teoria desempenhou apenas o papel de sensibilização teórica e não teve relação direta com a teoria substantiva construída.

\section{METODOLOGIA E PROCEDIMENTOS METODOLÓGICOS}

Esta pesquisa é de natureza qualitativa, com lógica abdutiva. Bandeira-de-Mello e Cunha (2007, p. 251) definem o processo de pesquisa da Grounded Theory como "um processo de 'idas e vindas', do nível conceitual, abstrato, ao nível dos dados, [o que] confere uma lógica de inferência abdutiva ao método". Maciel (2011, p. 60-61) afirma que "sua lógica abdutiva de investigação apresenta tanto características indutivas quanto dedutivas de geração de conhecimento. Isso significa que a análise (indutiva) dos dados, estabelecimento de proposições e validação (dedutiva) da teoria se enquadram num mesmo processo". O uso da Grounded Theory da maneira como foi concebida por Strauss e Corbin (2008) permite esse delineamento e é adequada para atingir o objetivo geral proposto. Na Grounded Theory as várias etapas da pesquisa ocorrem de modo concomitante e recursivo, em um processo altamente interligado. 
A Grounded Theory foi proposta em sua origem pelos sociólogos Glaser e Strauss (1967) como uma forma de se elaborar uma teoria com base em dados sistematicamente obtidos da pesquisa social. É uma metodologia com o objetivo de gerar teoria (STRAUSS e CORBIN, 2008). Strauss (1987, p. 5) afirma que a Grounded Theory é

[...] um estilo de se fazer análises qualitativas que incluem um número de características distintas, tais como amostragem teórica, e certas diretrizes metodológicas, tais como a produção de constantes comparações e o uso de um paradigma de codificação para assegurar desenvolvimento conceitual e densidade.

Alguns autores também a definem como método, como Tarozzi (2011, p. 17) que acrescenta que a Grounded Theory “é uma metodologia, isto é, um discurso racional global, uma orientação sobre o método e a análise teórica do mesmo, um modo de pensar (ou de construir) a realidade social e, ao mesmo tempo, um método", por conter em si um conjunto de instrumentos e procedimentos. De fato, o método é "um conjunto de procedimentos e técnicas para coletar e analisar dados [enquanto a metodologia é] uma forma de pensar sobre a realidade social e estudá-la" (STRAUSS e CORBIN, 2008, p. 17) e ambas as definições fazem parte da natureza da Grounded Theory.

Outras abordagens e orientações da Grounded Theory foram desenvolvidas por outros autores depois do trabalho inicial de Glaser e Strauss (1967), sendo as principais as de Strauss e Corbin (2008), Charmaz (2009) e Clarke (2005). Nesta pesquisa, a abordagem empregada da Grounded Theory é a de Strauss e Corbin (2008). O paradigma interpretativista é o de base da Grounded Theory e os pressupostos epistemológicos adotados são os do construtivismo, que contém em si o interacionismo simbólico. Quanto à ontologia, que precede a epistemologia, a realidade é vista como uma esfera de discurso simbólico (MORGAN e SMIRCICH, 1980). O paradigma interpretativista pressupõe que o conhecimento pode ser criado ou compreendido apenas partindo-se do ponto de vista dos indivíduos que fazem parte do ambiente estudado. Segundo esse paradigma, as ações e as interações dos indivíduos são baseadas em suas experiências e expectativas e, portanto, esse contexto deve ser considerado pelo pesquisador. Além disso, os significados apreendidos pelo pesquisador também são oriundos de suas interpretações, igualmente influenciadas por suas experiências e expectativas (HATCH, 1997). Segundo Tarozzi (2011, p. 50), "não existe a objetividade no conhecimento científico, existem suas interpretações". Essa afirmação talvez não se aplique a todas as áreas, mas a de ciências sociais é bastante suscetível a ela.

O período de coleta de dados, durante o qual também foi feita a codificação e a análise dos dados, a amostragem teórica, novas coletas e novas análises, foi de setembro de 2012 a fevereiro de 2013. Os dados foram coletados por meio de documentos e entrevistas, considerando também os memorandos e as notas de campo. Os entrevistados foram doze empresários de nove empresas de EdC. Com aqueles que se dispuseram a concedê-las pessoalmente e com os quais foi possível estabelecer uma agenda comum, assim foi feito. Com os demais, as entrevistas foram realizadas por Skype, telefone e outras, ainda, por e-mail (nesses casos foram feitos novos contatos por e-mail ou telefone requisitando maiores explicações às respostas ou fazendo, ainda, novas perguntas que se mostraram necessárias). As entrevistas foram gravadas com prévia autorização dos entrevistados, transcritas e analisadas logo em seguida, conforme indicam os pressupostos da Grounded Theory. Os entrevistados representaram satisfatoriamente a área substantiva dessa pesquisa: são de empresas antigas e recentes, empresários que já conheciam o Movimento dos Focolares e outros que não o conheciam, empresas que nasceram como de EdC e outras que já existiam e se adaptaram à proposta. São também empresas de diferentes portes e atividades, representando os três setores: indústria, comércio e serviço. De forma mais detalhada, foram entrevistados empresários das seguintes empresas: uma franquia da Multicoisas em Apucarana, Paraná (Entrevistados 2 e 6); a Cerâmica Cidade Nova, localizada em Sapopema e com escritório em Londrina, Paraná (Entrevistado 1); o grupo Prodiet, composto pela Prodiet Farmacêutica, Prodiet Nutrição Clínica, Prodiet Amostra, Prodiet Materiais Hospitalares e Prodiet Nordeste (Entrevistados 7 e 8); a Jova Marmoraria, localizada no Vale do Aço em Minas Gerais, que engloba as cidades principais de Ipatinga, Coronel Fabriciano e Timóteo (Entrevistado 3); Topus 3 Assessoria Empresarial, de Recife, Pernambuco (Entrevistado 4); Laboratório Santa Clara, na cidade de Cotia, São Paulo (Entrevistado 5); Real Plast Processos Industriais Ltda., de reciclagem de plásticos, em Salto, São Paulo (Entrevistados 9 e 10); Aja Soluções, sediada em Florianópolis, Santa Catarina, atuando na área de capacitação empresarial (Entrevistado 11); A. C. Cardoso, na área de consultoria, em Cotia, São Paulo (Entrevistados 1 e 12). 
A amostragem se desenvolveu durante o processo da pesquisa, conforme prevê a Grounded Theory (TAROZZI, 2011). O processo de amostragem teórica é aquele em que o pesquisador coleta, codifica e analisa os dados, faz comparações, questões analíticas e decide com base nisso quais dados coletar em seguida e onde procurá-los. O objetivo é encontrar novos dados que possam fornecer variações nas categorias em termos de suas propriedades e dimensões ou nas relações entre elas e desenvolver, assim, a teoria seguindo o modo como essa emerge dos dados. Na Grounded Theory não se fazem amostras de pessoas ou organizações, como na maioria das metodologias de pesquisa, mas fatos e incidentes (STRAUSS e CORBIN, 2008).

A amostragem foi feita tanto na codificação aberta quanto na axial e na seletiva, conforme orientação de Strauss e Corbin (2008). Na primeira, foi feita uma amostragem aberta ao que pudesse fornecer dados relevantes à descoberta, segundo os limites da acessibilidade. Para essa etapa, foram selecionados quatro empresários para as entrevistas e analisados os primeiros documentos da $\mathrm{EdC}$, aqueles relacionados à sua origem.

Na codificação axial, foi feita a amostragem relacional e variacional (STRAUSS e CORBIN, 2008), nas quais se procurou incidentes que permitissem identificar variações nos conceitos e relações entre eles. Nessa etapa foram analisados os documentos relacionados ao período de desenvolvimento da $\mathrm{EdC}$ a fim de refinar os conceitos e as relações entre eles e novos empresários foram entrevistados.

Na codificação seletiva, foi conduzido o processo de amostragem discriminada, em que "o pesquisador escolhe os locais, as pessoas e os documentos que vão maximizar as oportunidades de fazer análise comparativa" (STRAUSS e CORBIN, 2008, p. 204). Foram analisados mais documentos e refeita a análise de alguns pois algumas entrevistas mostraram uma possibilidade de leitura e interpretação distintas das já feitas. Nessa fase houve retorno aos empresários solicitando esclarecimentos com novas perguntas.

O processo de amostragem foi feito até o ponto em que as categorias se mostraram saturadas, ou seja, quando:

(a) nenhum dado novo ou relevante pareça surgir em relação a uma categoria, (b) a categoria esteja bem desenvolvida em termos de propriedades e de dimensões, demonstrando variação e (c) as relações entre categorias estejam bem estabelecidas e validadas (STRAUSS e CORBIN, 2008, p. 205).

Embora na Grounded Theory o processo de análise se dê também desde o início da pesquisa, em seguida a continuidade desse processo é mais bem detalhada.

\section{ANÁLISE DOS DADOS}

Ao se estudar as empresas da Economia de Comunhão, percebe-se que as teorias de estratégia e do management não se aplicam ou não explicam a dinâmica dessas organizações, por suas características peculiares encontradas, como fé, cultura de comunhão e bens relacionais. Decisões em tais empresas não se pautam pela maximização de retorno econômico, busca de poder econômico ou ambição gerencial (JOHNSON, WHITTINGTON e SCHOLES, 2011). Mas, ao mesmo tempo, sobrevivem em mercados competitivos e não podem ignorar tais circunstâncias. Mesmo as características também encontradas em outros tipos de organização têm na EdC especificidades. Isso pode ser observado, por exemplo, nas raízes da dimensão chamada influência axiológica. Desse modo, o uso da Grounded Theory foi fundamental para gerar com base na realidade observada uma teoria específica às empresas de $\mathrm{EdC}$, considerando a unicidade de suas características.

Antes de apresentar a análise dos dados, é importante fazer algumas considerações sobre a construção social da realidade, uma vez que esta pesquisa se propôs a elaborar uma teoria substantiva fundamentada nos dados que explique como são socialmente construídos os recursos que constituem a gestão de empresas baseada na Economia de Comunhão.

Para Berger e Luckmann (2009) - que fundamentam as reflexões que seguem sobre o tópico -, um conceito preliminar à "construção social da realidade" é a definição de realidade: uma qualidade que existe independentemente de nossa vontade de querer ou não que exista. A sociologia do conhecimento diz respeito ao modo como as realidades são admitidas e conhecidas nas sociedades humanas, no senso comum, ou seja, o interesse da sociologia do conhecimento está no mundo da vida cotidiana. É essa sociologia do conhecimento, segundo os autores, que deve tratar da construção social da realidade. 
O mundo da vida cotidiana pode se apresentar de duas maneiras: é a realidade dada como certa pelos membros da sociedade formada pela conduta das pessoas já internalizada, ou seja, objetiva; e também pode apresentar-se como realidade subjetiva, que diz respeito ao mundo que se origina no pensamento e na ação dos homens. Assim, a realidade da vida cotidiana apresenta-se a cada indivíduo como um mundo intersubjetivo, ou seja, um mundo no qual os indivíduos participam junto aos demais, o que pressupõe comunicação e interação. Sendo assim, a realidade é socialmente construída.

Partindo da comunicação e da interação, é possível apreender o outro por meio de esquemas tipificadores. As tipificações são produzidas à medida que há a observação do outro, a atribuição de motivo às suas ações e ao ver essas ações se repetirem. Desse modo, as tipificações são expressas em padrões específicos e esperados de conduta. Esse processo de tipificação é recíproco e acontece em situações sociais duradouras nas quais as ações habituais dos indivíduos se entrelaçam.

Essa tipificação influencia direta e continuamente o modo como indivíduos interagem uns com outros. A realidade da vida cotidiana é apreendida em um contínuo de tipificações e a soma dessas tipificações e dos padrões recorrentes de interação estabelecidos por meio delas forma a estrutura social. Esses elementos, apresentados por Berger e Luckmann (2009), explicam o processo de construção social da realidade assumido neste trabalho.

Isso posto, passa-se à análise dos dados da presente pesquisa. A análise dos dados não é um processo estruturado, estático ou rígido na Grounded Theory, mas um processo dinâmico, criativo e de fluxo livre, com movimentos constantes do pesquisador (STRAUSS e CORBIN, 2008). As categorias analíticas não podem ser predefinidas constitutiva e operacionalmente, conforme pesquisas que se valem da lógica dedutiva, mas, ao contrário, na Grounded Theory a definição de categorias se dá ao longo do processo de tratamento e análise dos dados.

O início do processo analítico deu-se por meio da microanálise, ou seja, a análise detalhada dos documentos e das entrevistas, por linhas e frases e as primeiras codificações. A microanálise foi necessária, sobretudo na fase inicial, para que fossem geradas as categorias iniciais e para descobrir as primeiras relações entre os conceitos. Envolveu o exame e a interpretação dos dados, oriundos das entrevistas, notas de observações de campo, memorandos e de toda a literatura não técnica disponível (STRAUSS e CORBIN, 2008).

A microanálise é uma combinação de codificação aberta e axial. A codificação aberta é o primeiro passo analítico e é por meio dela que "os conceitos são identificados e suas propriedades e suas dimensões são descobertas nos dados" (STRAUSS e CORBIN, 2008, p. 103). Isso se deu por meio da abertura dos textos, com a finalidade de expor as interpretações e os significados neles contidos, a fim de gerar conceitos ou categorias que representassem os fenômenos. Estes, por sua vez, têm a capacidade de explicar o que está acontecendo, dado que são padrões repetidos que representam as respostas das pessoas a determinadas situações (STRAUSS e CORBIN, 2008).

Para auxiliar na organização e na codificação de entrevistas, documentos, notas de campo e memorandos e em todo o processo de análise, foi adotado o programa NVivo, versão 9 - programa de apoio à análise qualitativa. Os códigos são chamados de nós no programa e os incidentes ou eventos, referências.

O número total de nós nessa primeira etapa foi de 92, com 234 referências. Os nós foram, então, analisados em separado, examinados e comparados em busca de pontos similares e diferentes, o que gerou as primeiras categorias, compreendidas como o agrupamento em forma de conceitos abstratos dos elementos considerados similares em termos conceituais ou de significado, ou seja, os agrupamentos dos conceitos que representam os fenômenos. Para fazer esse agrupamento é necessário olhar os conceitos e perguntar-se "o que está acontecendo", e aí surgirá a categoria, à qual deverá ser atribuído um nome (STRAUSS e CORBIN, 2008).

Depois desse trabalho de categorização, os nós (que passaram a representar as categorias) foram reduzidos a 11 e, posteriormente, a sete, conforme apresentado no tópico a seguir. Identificadas as categorias, o trabalho foi o de aumentar o conhecimento em relação ao conceito, delineando as propriedades da categoria - ou suas características específicas - e suas dimensões - ou a variação de cada propriedade em um intervalo contínuo. A partir desse esforço foi possível estabelecer padrões, que "são formados quando grupos de propriedades se alinham ao longo de várias dimensões" (STRAUSS e CORBIN, 2008, p. 118). 
Elaboradas a conceituação, a definição, o desenvolvimento de categorias em termos de propriedades e dimensões e o estabelecimento de padrões - que compõem a codificação aberta -, a próxima etapa de análise foi a codificação axial, que consistiu em um reagrupamento dos dados depois da codificação aberta, associando categorias ao nível de suas propriedades e dimensões.

Foram feitos, então, os quatro procedimentos básicos recomendados por Strauss e Corbin (2008, p. 126):

(1) organizar as propriedades de uma categoria e suas dimensões, uma tarefa que começa na codificação aberta; (2) identificar a variedade de condições, ações/interações e consequências associadas a um fenômeno; (3) relacionar uma categoria à sua subcategoria por meio de declarações que denotem como elas se relacionam umas às outras; (4) procurar nos dados pistas que denotem como as principais categorias podem estar relacionadas umas às outras.

O quarto passo se deu simultaneamente à codificação seletiva. Na codificação axial, o objetivo foi contextualizar o fenômeno para identificar como as categorias se manifestam em termos de suas propriedades e dimensões. Questões que ajudaram a alcançar esse objetivo foram as que identificavam o "porquê ou de que forma, onde, quando, como e com que resultados" (STRAUSS e CORBIN, 2008, p. 127).

Nesse ponto da pesquisa, fez-se a amostragem relacional e variacional (STRAUSS e CORBIN, 2008), em que se procurou incidentes que permitissem identificar variações nos conceitos e as relações entre eles. Nessa etapa, foram analisados os documentos relacionados ao período de desenvolvimento da EdC para refinar os conceitos e suas relações e feitas novas entrevistas. As categorias que emergiram desse processo foram: (1) influência axiológica; (2) cultura de comunhão; (3) hábitos e costumes que retroalimentam o estilo de gestão; (4) bens relacionais; (5) empirismo e adequação; (6) ética; e (7) fé.

A influência axiológica foi a categoria mais densa que emergiu dos dados. Ao questionar a estrutura, ou seja, o porquê de os fenômenos ocorrerem, os valores dos empresários se destacaram, consistindo em recursos para que as empresas pudessem atuar segundo a gestão de Economia de Comunhão. Isso ficou claro no discurso dos empresários, conforme alguns trechos das entrevistas exemplificam:

O DNA da empresa da EdC, que parte do empresário, do proprietário, é que ele seja esse homem novo que nós falamos, que ele seja esse indivíduo renovado pelos valores, que nós chamamos de valores cristãos, porque em cima desses valores, desses princípios é que devem nortear a tomada de decisão dentro da empresa em relação a todas as partes interessadas, os stakeholders, que a gente chama. (Entrevistado 1)

O meu avô foi vicentino, o meu pai tinha um cartório. O movimento dele era superpequeno, porque ele alertava as pessoas simples: "Você está entendendo o que significa esse papel que você está assinando? Você sabe que ele pode vender sua casa?" O que acontecia? O advogado não voltava mais lá. A vida inteira vimos a família da entrevistada 6 de industriais dizendo: "Não, não vamos fechar, porque são tantas famílias". Isso a vida inteira. Então tem história atrás disso, mas a EdC veio dar uma refinada às formas de gestão mais modernas. (Entrevistado 2)

Diversos outros trechos dos mesmos entrevistados e de todos os outros demonstram que os primeiros recursos que constituem a gestão de EdC são os valores que eles adquiriram ao longo da vida e os influenciaram na escolha de aderir à EdC e nas práticas cotidianas coerentes com essa abordagem de gestão. A categoria pode ser dividida em duas subcategorias: (1) os valores dos empresários; e (2) a origem dos valores dos empresários. As propriedades da primeira subcategoria são: (i) honestidade; (ii) solidariedade; (iii) desapego material; (iv) altruísmo; e (v) justiça. As propriedades da segunda subcategoria são: (i) valores familiares; (ii) valores pessoais precedentes; (iii) valores religiosos; e (iv) valores do Movimento dos Focolares.

A categoria cultura de comunhão emergiu uma vez que os valores cristãos foram mencionados por diversos empresários. Isso exigiu uma nova amostragem teórica para a compreensão do que distingue a gestão de Economia de Comunhão de uma 
gestão baseada somente em valores cristãos. Dois elementos apareceram em todas as respostas: a coletividade e a comunhão. Alguns citaram em separado esses dois termos, ao passo que outros inseriram coletividade no conceito de comunhão.

\begin{abstract}
Outro princípio é o papel do lucro. O lucro não como um bem pessoal, mas mais comunitário. Ter essa concepção de gestão de que a empresa não é sua, não é do proprietário mais, é um negócio que precisa gerar lucro e esse lucro precisa circular. (Entrevistado 3)
\end{abstract}

Eu acho um desafio. É essa abertura, porque o empresário muitas vezes está voltado ao lucro pessoal. o desafio é esse abrir. De certa forma essa experiência que eu tento fazer, eu vejo que é muito cômodo você colocar um dinheiro em comum, mas essa mudança de mentalidade, de abertura, essa convicção de que uma empresa é partilhada, é de comunhão. (Entrevistado 3)

O conceito amplo de comunhão contém em si as propriedades que caracterizaram a categoria nomeada cultura de comunhão: (i) doação de parte do lucro; (ii) inserção dos stakeholders na abordagem de gestão; (iii) interação com outros empresários da EdC; (iv) comunicação com a Associação Nacional por uma Economia de Comunhão (Anpecom); (v) comunicação com grupos regionais da EdC (comissões e grupos de estudo e trabalho); (vi) colaboração entre as empresas de EdC; e (vii) participação em congressos de EdC.

A cultura de comunhão constrói, caracteriza e constitui a gestão de EdC à medida que a troca de experiências entre os empresários de EdC ajudam no direcionamento ou até no redirecionamento da gestão de EdC presente em suas empresas. A divisão do lucro é a característica que deu origem à EdC, como resposta às necessidades das populações que vivem em estado de pobreza, e, portanto, também caracteriza e constitui a gestão de EdC. Os stakeholders, quanto mais são inseridos nessa dinâmica de comunhão, mais tendem a colaborar com a atuação dos princípios da EdC nas empresas a eles relacionadas. A ajuda que há entre as empresas da EdC também é oriunda dessa cultura e reflexo dela.

Os hábitos e costumes são socialmente construídos com base nas relações entre os diversos stakeholders que, por sua vez, são influenciadas pelos valores e princípios da gestão de EdC. Da mesma maneira, esses hábitos e costumes retroalimentam a abordagem de gestão, que é reforçada por eles. Isso pode resultar em cultura organizacional. Nem sempre chega a esse ponto, por isso mantiveram-se hábitos e costumes na categoria em vez de nomeá-la cultura organizacional.

A categoria hábitos e costumes que retroalimentam a abordagem de gestão foi caracterizada pelas seguintes propriedades: (i) colaboração entre os funcionários; (ii) ajuda dos empresários aos funcionários; (iii) ambiente físico de trabalho; (iv) descentralização; (v) ensino de tarefas; (vi) comprometimento; (vii) responsabilidade; (viii) profissionalismo; (ix) apoio ao aprendizado; $(x)$ apoio para a entrega de competências; e (xi) momentos de oração e/ou reflexão. Exemplos dessas propriedades estão nos trechos das entrevistas a seguir.

[...] pra mim a EdC é uma cultura, como um modo de ser, um modo de ver, como Chiara definiu desde o começo. [...] eu considero que a EdC é um estilo de vida proposto não para as pessoas físicas, mas para as empresas, que é muito mais do que você colocar em comum os lucros da empresa, vai muito além disso, ela cria uma identidade para a empresa em relação ao mundo. (Entrevistado 4)

[...] é uma nova cultura, é uma mudança de cultura, de conceito de vida que a gente vem implantando e isso é lento. A gente consegue ver mudanças porque a gente também procura investir na empresa, em tecnologia, em treinamento, em organização, em planejamento, inovação, descentralização, delegação de poder. (Entrevistado 3)

As especificidades de cada empresa, empresário, pessoal e stakeholders fazem que os hábitos e costumes construídos nas empresas e que as caracterizam e constituem sejam distintos em cada empresa. Há similaridades deles entre as empresas por ter bases de valores semelhantes e a cultura de comunhão característica da EdC, mas, assim como os recursos tangíveis variam de acordo com a atividade em qualquer empresa, também os hábitos e os costumes são influenciados pelas pessoas e pelos contextos dos quais fazem parte. $O$ exemplo dado pelo empresário é visto como fator determinante para a construção e a retroalimentação desses hábitos e costumes nas empresas de EdC. 
O nome da categoria bens relacionais remete ao conceito apresentado por Benedetto Gui (2001), segundo o qual, na esfera das relações interpessoais, criam-se bens que são relevantes também para a economia; são os bens que nascem de relacionamentos, como a amizade e a confiança. Em diversas entrevistas e também nos documentos esse termo se destacou. Houve casos em que os empresários entrevistados disseram ser os bens relacionais sua principal referência de gestão de EdC. Outros os mencionaram indiretamente. Os exemplos a seguir ilustram os dois casos.

A valorização do ser humano na sua totalidade. Colocar a pessoa humana acima de qualquer coisa. Preservar os relacionamentos, a criação de relacionamentos, a geração de relacionamentos novos. (Entrevistado 3)

\begin{abstract}
Muito mais que montar o Santa Clara Laboratório, para nós o grande motivo era termos uma empresa da EdC, com seus princípios e fundamentos, suas bases e com um objetivo obstinado que é compor com outras pessoas a busca por uma sociedade renovada, colocando sempre em relevo a dignidade de cada um e priorizando a harmonia do relacionamento entre nós, [...] os bens relacionais foi uma descoberta fantástica. (Entrevistado 5)
\end{abstract}

A categoria compõe-se das seguintes subcategorias: (1) relacionamento com os funcionários; (2) relacionamento com os clientes; (3) relacionamento com os fornecedores; e (4) relacionamento com os concorrentes. As propriedades comuns às subcategorias foram: (i) confiança; (ii) respeito; (iii) reciprocidade; e (iv) amizade. Somadas a essas, as específicas da subcategoria (1): (v) colaboração para bom clima organizacional; (vi) presença em confraternizações; e (vii) atitudes de ajuda e solidariedade. Específicas da subcategoria (2): (v) fidelidade do cliente; e (vi) cortesia. Propriedade específica da subcategoria (3): (v) disponibilidade em ajudar. Por fim, da categoria (4): (v) possibilidade de parcerias.

Os princípios da EdC estimulam a constituição de bens relacionais, uma vez que preveem aspectos como ética e cultura de comunhão que são elementos fundamentais para a geração de confiança, reciprocidade e os demais bens relacionais. Como o próprio termo sugere, são bens que nascem das relações, o que reforça a ideia de algo que constrói, caracteriza e constitui a abordagem de gestão, e não algo que "a empresa tem", conforme pressupõe a lógica funcionalista (SMIRCICH, 1983).

É importante salientar que os bens relacionais também têm impacto econômico nas empresas, tanto em termos de ganhos quanto de custos. Ganhos no sentido daquilo que esses bens oriundos de relações boas e sustentáveis geram e custos tanto para sua construção - até que os stakeholders estejam alinhados a essa perspectiva de relacionamento - quanto para sua manutenção. O clima organizacional depende diretamente desses bens.

Empirismo e adequação foi uma categoria peculiar que emergiu dos dados. Se, por um lado, há as linhas de gestão e documentos de base da EdC, por outro, o que prevalece como recurso que de fato constitui a abordagem de gestão da EdC nas empresas é a própria interpretação de cada empresário acerca da EdC e a adequação dela à sua atividade, que se traduz em práticas. $\mathrm{A}$ forma de conduzir o cotidiano da empresa bem como o foco em determinado princípio da EdC depende diretamente disso.

Alguns elementos de destaque foram comuns entre empresas do mesmo setor, como: no caso da empresa de venda no varejo, o foco encontrado foi no relacionamento com os funcionários entre eles, o que gera um ambiente de trabalho de colaboração mútua, respeito, confiança e simpatia. No caso da empresa de consultoria e do escritório contábil, o aspecto da ética prevaleceu. Na indústria, a qualidade do produto, treinamento e atenção ao impacto ambiental. Foi possível notar que, para alguns empresários, os princípios da EdC não estão claros, entretanto eles a compreendem como uma cultura que permeia as atividades, os relacionamentos e os objetivos da empresa e a prática desse entendimento conduz à abordagem de gestão de EdC.

Os outros aspectos da EdC também estavam presentes, todavia a natureza da atividade e a interpretação dos empresários os levaram a focar elementos específicos, que são as propriedades dessa categoria: (i) adequação segundo os próprios valores; (ii) adequação à natureza da atividade; e (iii) adequação segundo a resposta dos stakeholders.

A gestão de EdC é observada nas práticas das empresas, oriundas da interpretação e da adequação dos empresários e da resposta dos stakeholders. É na experiência, tanto da própria empresa quanto naquela das demais empresas de EdC, que essa abordagem de gestão se materializa e adquire sentido. Devido a isso, a gestão, segundo os pressupostos da EdC, se torna única em cada empresa, embora mantenha os elementos básicos que a caracterizam. 
Ao ser lançada em 1991, a Economia de Comunhão previa inicialmente a comunhão do lucro e não mencionava elementos relativos à gestão. Entretanto, já no início os empresários que adotaram essa abordagem em suas empresas inseriram espontaneamente um princípio de base para diversas ações cotidianas: a ética nos diversos aspectos relativos à atividade.

Esse princípio passou, então, a permear o relacionamento das empresas de EdC com seus stakeholders, o que implicou a perseguição de alguns elementos, que constituem as propriedades dessa categoria: (i) cumprimento dos compromissos; (ii) informação precisa sobre o produto ou serviço oferecido; (iii) qualidade do produto ou serviço oferecido; (iv) pagamento integral dos tributos; (v) cumprimento da legislação; (vi) não pagamento de propinas; (vii) não difamação dos concorrentes; e (viii) ética nas especificidades do negócio. Um exemplo dessas propriedades está na fala de um entrevistado:

A partir daí criou-se um novo conceito até nas relações com os clientes, na questão da ética... porque no nosso serviço, na nossa função, muitas vezes a gente é convidado a fazer coisas não éticas, dar uma declaração que não é verdade, fazer um balanço favorável com números favoráveis para a obtenção de um empréstimo... enfim, isso está cada vez mais difícil até mesmo pela modernização dos sistemas fiscais, isso dificulta muito e é uma boa desculpa pra gente, mas há dez anos isso não existia, então a partir daí, quando chegava alguma solicitação de cliente nesse sentido, elas nem sequer deixavam chegar a mim, elas diziam: não, seu (Entrevistado 4) não aceita fazer isso não. Parava ali mesmo. (Entrevistado 4)

A ética apresentou-se como um recurso básico para a gestão de EdC, uma vez que estabelece coerência entre os princípios propostos pela EdC e as ações cotidianas relacionadas à empresa e, por isso, mostrou-se como um elemento caro aos empresários de EdC. Os dados mostraram que esse recurso contribui para a construção dos bens relacionais e para a sustentabilidade do negócio a longo prazo.

Diversos são os termos empregados para expressar a categoria denominada "fé". A presença do chamado "Sócio invisível" (Deus) e da "Providência" (intervenção divina que provê aquilo de que necessitam) é concebida pelos empresários como recurso indispensável à gestão pautada na Economia de Comunhão. Além disso, a fé na missão da empresa como uma empresa de EdC também compôs essa categoria.

Um exemplo dessa categoria aparece em um depoimento:

[...] o Sócio Invisível é matemático, não é uma coisa subjetiva. [...] Houve um dia em que eu estava com dificuldades pra cumprir os compromissos daquele dia, eu tinha dinheiro mas não tinha dinheiro disponível, tinha um dinheiro que estava em cheques que ainda não tinham sido compensados e era um tempo de vacas magras pra gente também, então eu pedi e confiei: daqui para o final do dia vai aparecer essa..., de alguma forma vai aparecer, eu não tinha de onde tirar, mas eu sabia que de uma forma ou de outra ia aparecer. E chegou lá [no escritório] não um cliente, mas um amigo, com quem eu tinha trabalhado na empresa dele por dez anos e era uma pessoa que a empresa faliu, ele não tinha mais condições financeiras de pagar honorários nem nada e toda vez que ele precisava de alguma coisa eu fazia espontaneamente alguns serviços, alguns trabalhos pra ele e entre esses trabalhos estava o de viabilizar uma indenização de um dinheiro pelo Incra, por umas terras dele que foram desapropriadas. E nessa manhã, exatamente nesse dia, ele foi no meu escritório me fazer uma visita, conversar comigo, e eu como de costume atendi ele na minha sala e ele falou: 'olha, eu queria deixar uma coisa aqui com você, resolvi aquele problema da terra, o Incra indenizou e eu queria deixar isso aqui com você; não é um pagamento que eu estou fazendo para vc, é apenas uma retribuição pela força que você deu pra gente" e tal tal tal... [...]. Quando ele saiu eu fui abrir o envelope e a quantia era um pouco a mais do que aquilo que eu estava precisando naquele dia [...]. Pra mim isso era uma prova matemática, por isso eu digo a você. Já tivemos vários outros momentos de chegar a providência quando menos se espera, mas pra mim esse foi muito significativo, esse me marcou. Por isso que eu digo que não é uma coisa subjetiva, é uma coisa bem objetiva. (Entrevistado 4)

Essa categoria tem três propriedades: (i) Sócio invisível; (ii) Providência; e (iii) fé no propósito da empresa como empresa de EdC. A próxima etapa da pesquisa foi a codificação seletiva, cujo intuito foi integrar as categorias a fim de formar um esquema teórico maior. Nesse ponto foi importante descobrir a categoria central, que é aquela que representa o tema principal da 
pesquisa. Ela é abstrata, incorpora em si outras categorias importantes e também foi definida em termos de suas propriedades e dimensões (STRAUSS e CORBIN, 2008).

A Grounded Theory é caracterizada pelo chamado constant comparative method (WELLS, 1995) - método comparativo constante ou método das comparações constantes. Desse modo, análises comparativas foram constantes em todas as etapas da pesquisa, sendo feitas primeiro entre incidentes e, em seguida, feitas as comparações teóricas.

Nas comparações por incidentes, cada um foi comparado a outro "no nível de propriedade ou dimensional [...] em busca de similaridades e diferenças e é agrupado ou colocado em uma categoria" (STRAUSS e CORBIN, 2008, p. 84). As comparações teóricas visaram a estimular o pensamento sobre propriedades e dimensões e dirigir a amostragem teórica (STRAUSS e CORBIN, 2008). A saturação teórica se deu quando, durante a análise, não surgiram novas propriedades, dimensões ou relações nas categorias e "dentro dos limites de tempo e de dinheiro disponíveis", conforme apontam Strauss e Corbin (2008, p. 273).

As categorias se sobrepuseram em alguns aspectos, visto que são compostas de diversas propriedades subjetivas e codependentes, como no caso das categorias influência axiológica e cultura de comunhão: os valores são a base para que se crie a cultura de comunhão e esta, por sua vez, reforça e define os valores. A cultura de comunhão e os valores influenciam diretamente a construção social dos hábitos e costumes nas empresas de EdC e são essas ações que retroalimentam e caracterizam a gestão de EdC.

É importante destacar que o processo de construção social se dá de duas formas nas empresas de EdC: dentro das empresas que trabalham sob a filosofia da EdC e entre as empresas que trabalham sob a filosofia da EdC. Embora as entrevistas tenham sido apenas com empresários, o conteúdo delas e a análise documental evidenciou que tais princípios estão incorporados nessas empresas e também ali são construídos socialmente. Isso fica claro na categoria empirismo e adequação.

Essa abordagem sobre a gestão é interpretada por cada empresário e adequada às especificidades de sua empresa. Além disso, muitos empresários compreendem a EdC só no próprio contexto empírico, ou seja, reconhece essa abordagem de gestão nas experiências cotidianas que acontecem em suas empresas (categoria empirismo e adequação). A configuração da EdC em cada empresa, todavia, não faz que a EdC perca suas características e identidade comuns. Isso se dá porque os valores e a cultura de comunhão permanecem como as bases da EdC (categorias influência axiológica e cultura de comunhão).

A categoria ética está diretamente relacionada às demais categorias. Valores geram e motivam os princípios éticos que as pessoas adotam e são esses princípios que regem os relacionamentos e ajudam a gerar os bens relacionais (categorias influência axiológica e bens relacionais). A ética não é o único fator que gera esses bens, mas, sem sua presença, eles não podem existir. Os hábitos e os costumes são construídos com base em princípios éticos, de valores praticados e de bens relacionais (categorias construção social de hábitos e costumes que retroalimentam a abordagem de gestão, ética, influência axiológica e bens relacionais).

A fé, tanto na intervenção divina quanto na missão da empresa de ser uma empresa de EdC, motiva o empresário a continuar a dirigir sua empresa segundo esse estilo de gestão, não obstante as dificuldades. A intervenção divina é vista como o cêntuplo por esses empresários (categoria fé). A base de valores dos empresários influencia sua sensibilidade a respeito da percepção da intervenção divina (categorias influência axiológica e fé). Eles veem nisso uma confirmação e uma recompensa por sua conduta. A comunicação com os demais empresários, com pessoas ajudadas pela parte do lucro destinada aos necessitados, a participação em congressos e nos demais grupos, formais ou não, ligados à EdC fazem aumentar no empresário a fé em seu negócio e em suas escolhas (categorias fé e cultura de comunhão).

Da análise da integração entre as categorias, emergiu como categoria central a influência axiológica. Essa categoria, conforme preveem Strauss e Corbin (2008), está relacionada a todas as outras e aumenta a capacidade explanatória delas. Representa também o cerne da teoria substantiva gerada nesta pesquisa, ou seja, de que a influência axiológica dos empresários e a cultura de comunhão são os elementos determinantes para a construção social dos recursos constitutivos da gestão de Economia de Comunhão.

Pode-se indagar se a fé não seria a categoria central, dado que em diversos casos essa é a base das outras opções subsequentes. Todavia, dois elementos fundamentam a escolha da influência axiológica como categoria central: (1) a frequência com que aparece nos dados - um dos critérios de escolha da categoria central propostos por Strauss e Corbin (2008) - foi maior do que todas as outras categorias. Nas entrevistas com os empresários, a influência dos valores na escolha de inserir e manter a lógica da EdC em suas empresas apareceu com maior frequência que a categoria fé. (2) Nos dados apareceram casos em que a fé não era elemento fundamental - isso se explica devido à EdC ser aberta inclusive a pessoas que não têm 
nenhuma religiosidade. Em contrapartida, os valores estavam presentes em todos os casos, como aquilo que deu sentido e justificou a própria adesão dos empresários e manutenção dessa gestão em suas empresas. Desse modo, quando as condições variaram, a explicação permaneceu válida (STRAUSS e CORBIN, 2008).

Neste trabalho não se pretendeu fazer juízo de valor sobre os princípios da Economia de Comunhão, apenas entender em que medida são apropriados em empresas que a endossam e como influenciam o uso de recursos e estilo de gestão.

\section{APRESENTAÇÃO DA TEORIA SUBSTANTIVA}

Os pressupostos ontológicos e epistemológicos assumidos como base para a teoria substantiva são o da realidade vista como uma esfera de discurso simbólico (MORGAN e SMIRCICH, 1980; SMIRCICH, 1983) e socialmente construída (BERGER e LUCKMANN, 2009); os pressupostos epistemológicos adotados são os do construtivismo e do interacionismo simbólico.

O paradigma adotado foi o interpretativista, que pressupõe que o conhecimento pode ser criado ou compreendido só do ponto de vista dos indivíduos que fazem parte do ambiente estudado (HATCH, 1997). A partir dele foi possível analisar o processo social que originou a teoria substantiva: o processo social de interpretação que leva à compreensão dos recursos socialmente construídos que constituem a abordagem de gestão de EdC nas empresas que a adotam.

O conceito de recurso foi revisitado para expressar as concepções oriundas das escolhas ontológica e epistemológica e, ainda, caracterizar o que representam para a área substantiva em estudo. O trabalho de Smircich (1983) permitiu o desenvolvimento desse conceito. Esse autor diferencia a concepção de cultura como variável - o que a empresa tem, em uma lógica funcionalista - e como metáfora - ou o que a empresa é, segundo uma lógica simbólica. Para a área substantiva em estudo, a noção de recursos se aproxima mais da segunda abordagem, por ser a ação simbólica fator fundamental para a análise da construção social dos recursos.

Todavia, a epistemologia construtivista adotada nesta teoria substantiva fornece ainda um elemento adicional para a concepção de recurso: é aquilo que constrói o que a empresa é e, na condição de elemento que a constrói, é também seu elemento constituinte, é intrínseco a ela, faz parte de sua natureza. Sendo assim, o conceito de recurso adaptado à área substantiva ao qual a Teoria Axiológica de Comunhão se refere, é: os elementos que - por meio de seu conjunto de serviços - constroem, caracterizam e constituem a gestão de empresas baseada na Economia de Comunhão.

A integração das categorias em torno da categoria central gerou o conjunto de proposições com a capacidade de explicação esperada dessa teoria substantiva. As proposições - que eram 22 já em sua segunda etapa, validadas - foram reformuladas com base nessa integração, originando as proposições definitivas, ou seja, os conceitos que constituem a Teoria Axiológica de Comunhão, apresentadas a seguir.

Proposição 1: os valores dos empresários influenciam diretamente a adoção e a manutenção da gestão de EdC nas empresas, construindo, caracterizando e constituindo essa gestão.

A heterogeneidade e a subjetividade dos serviços contidos nos valores dos empresários, somados à sua interpretação e adequação dos princípios da EdC no contexto empírico fazem que a abordagem de gestão da EdC nas empresas adquira combinações específicas. Mesmo distintas, essas combinações mantêm a identidade da EdC, uma vez que a cultura de comunhão presente a caracteriza.

A cultura de comunhão emergiu como um dos recursos mais característicos da gestão de EdC, pois mostrou-se como o fator de distinção entre uma abordagem de gestão cristã e de EdC. A EdC contém em si os valores cristãos - e também os outros tipos de valores mencionados - mas o que a caracteriza de fato é a cultura de comunhão, ou seja, a concepção ampla de coletividade e a repartição do lucro. A cultura de comunhão é construída baseada em uma dupla hermenêutica: a interpretação de viés comunitário do Evangelho pela fundadora do Movimento dos Focolares e de sua primeira comunidade e a interpretação dessa leitura pelo empresário. Desse modo, emergiram a segunda e a terceira proposições:

Proposição 2: a cultura de comunhão torna-se uma cultura por meio da prática, da interação e da comunicação interna e com as demais pessoas e grupos coligados à EdC, caracterizando e constituindo as empresas de EdC. 
Proposição 3: a caracterização da gestão da EdC se dá por meio da experiência coletiva, de comunicação e de comunhão dentro da empresa assim como, em certa medida, com os stakeholders e com os demais empresários da EdC e seus grupos representativos formais e informais.

Isso se expressa pela divisão do lucro nas partes propostas, nas relações cotidianas com e entre os stakeholders e na rede de colaboração entre os empresários de EdC.

A categoria central está relacionada também com a categoria hábitos e costumes que retroalimentam a abordagem de gestão. A influência axiológica do empresário com os princípios propostos pela EdC e a adesão dos funcionários a eles são a base para a construção dos hábitos e costumes dentro da organização que concorrem para a gestão de EdC. Isso faz que esses hábitos e costumes sejam específicos em cada empresa de EdC e a caracterize e, à medida que são compreendidos como parte da organização, passam a compor seu patrimônio, com a tendência de se manter ao longo do tempo, mesmo se houver mudanças no quadro de pessoal. Essas relações são apresentadas na proposição 4.

Proposição 4: a construção social dos hábitos e dos costumes relacionados aos princípios da Economia de Comunhão é influenciada por esses princípios, pelos valores dos empresários, pelo exemplo e apoio ao aprendizado que dão aos funcionários e pelas relações que se estabelecem no ambiente de trabalho. Isso faz que esses hábitos e costumes sejam específicos para cada empresa, caracterizando-a e tornando-se parte dela com o passar do tempo. Ao mesmo tempo que são construídos, os hábitos e os costumes também fortalecem essa abordagem de gestão, configurando um processo de retroalimentação entre eles.

A ética também emergiu da pesquisa como elemento que constrói, caracteriza e constitui a gestão de EdC. Está diretamente relacionada às demais categorias, sobretudo à categoria central influência axiológica do próprio empresário, por representar a origem e o viés de sua interpretação acerca do que compreende por ética. Emergiu também como elemento fundamental para a sustentabilidade e a perenidade do negócio. Nesse sentido, do contexto da área substantiva resultaram as seguintes proposições:

Proposição 5: o recurso ética é construído socialmente na área substantiva por meio da influência axiológica.

Isso se dá como uma combinação de valores familiares, sociais, religiosos e valores transmitidos pelo Movimento dos Focolares adotados pelo empresário.

Proposição 6: a atuação de princípios éticos nas práticas cotidianas das empresas de EdC está relacionada à sustentabilidade e à perenidade do próprio negócio, influenciando-o positivamente, sobretudo a longo prazo.

Além disso, esse recurso é a base para a construção de outros, como os bens relacionais e os hábitos e costumes relacionados à gestão de EdC. Não é o único recurso que gera esses outros, mas é condição necessária para que possam ser construídos.

Proposição 7: os princípios éticos adotados pelo empresário regem os relacionamentos e, quando compartilhados, integram o processo de construção social dos bens relacionais e dos hábitos e costumes que constituem a gestão de EdC.

A respeito dos bens relacionais é importante destacar que sua construção social também está relacionada à influência axiológica do empresário (conforme é possível inferir da proposição 5) e da resposta condizente dos stakeholders, a fim de que seja algo recíproco. Os bens relacionais interferem diretamente no clima organizacional e nos relacionamentos com os demais stakeholders. Há custos monetários e de tempo empregados para essa construção. As proposições a seguir apresentam essas relações.

Proposição 8: os valores dos empresários e a experiência relacional entre os indivíduos influenciam a construção dos bens relacionais. Sua manutenção se dá à medida que são preservadas as relações de confiança e respeito de modo que haja reciprocidade.

Proposição 9: o clima organizacional condizente com a EdC é resultado da combinação dos diversos bens relacionais. Quanto mais rápida a recuperação das relações quando essas apresentam problemas, menores serão os impactos negativos no clima organizacional. 
A categoria empirismo e adequação emergiu dos dados de maneira peculiar e estreitamente relacionada à categoria central. Os valores dos empresários influenciam suas interpretações sobre os princípios da EdC. A partir disso, eles adequam esses princípios à realidade de sua empresa. A EdC passa a ser, nas empresas, não algo que elas adotam, mas algo em que se tornam - visão semelhante à de Smircich (1983) com relação à cultura. E se tornam só por meio da ênfase na experiência, não por meio de discursos ou normas impostas.

Embora a interpretação precedida pela influência axiológica do empresário gere uma adequação dos princípios da Economia de Comunhão nas empresas, observou-se que a cultura de comunhão preserva a identidade comum entre as empresas de EdC. Ela se sobrepõe às diversas interpretações e adequações e também à natureza das atividades e à sua localização geográfica. A análise da relação entre as categorias resultou nas seguintes proposições:

Proposição 10: a cultura de comunhão preserva a identidade comum entre as empresas de EdC, não obstante as diferenças sistemáticas entre essas empresas, que são relativamente estáveis, por ser fruto das escolhas dos empresários e dos seus valores.

A categoria fé, por fim, foi definida como a percepção da intervenção divina - o que no âmbito da EdC são chamadas de sócio invisível e Providência - e a fé no propósito da empresa como empresa de EdC e não no contexto muito mais amplo ao qual a palavra fé se refere. Tendo isso considerado, a fé, além de constituir algo íntimo do empresário, está relacionada à influência axiológica e à cultura de comunhão, que a estimula e renova. A proposição oriunda dessa relação é:

Proposição 11: a percepção da fé do empresário que adere à EdC é construída por meio da influência axiológica e da interação com o meio da EdC.

Isso se dá pela participação em congressos, troca de experiências com outros empresários ou até mesmo pelo conhecimento das experiências das pessoas em situação de necessidade às quais foram destinados parte dos lucros das empresas de EdC.

Essas proposições compõem a teoria substantiva gerada nesta pesquisa: a Teoria Axiológica de Comunhão. Essa teoria explica que os empresários exercem influência direta na construção social dos recursos que constituem a gestão de empresas baseada na EdC, principalmente por meio de seus valores - construídos em sua história e decorrentes de suas escolhas acerca dos valores familiares, religiosos e do Movimento dos Focolares que lhe foram apresentados e por eles experienciados ao longo da vida - e da cultura de comunhão proposta pela EdC e adotada pelos empresários. Daí o nome "Teoria Axiológica de Comunhão".

O gestor desempenha o papel daquele que interpreta, age e promove a interação tanto entre os próprios recursos - que por vezes, quando combinados, geram outros recursos - quanto entre os stakeholders, para construir e manter a gestão de EdC em suas empresas. São eles que motivam as pessoas e articulam os recursos, originando uma abordagem própria de gestão de EdC.

A cultura de comunhão, bem como a experiência coletiva que ela pressupõe, é construída com base na proposta do empresário e torna-se de fato cultura na empresa quando encontra adesão principalmente dos funcionários. Essa cultura se expressa ainda na comunicação, na troca de experiências e na ajuda mútua entre as empresas de EdC. Os hábitos e os costumes relacionados aos princípios da EdC também são construídos baseados na motivação do empresário, de seus valores e de seus exemplos. Os hábitos e os costumes que se formam, por sua vez, retroalimentam a gestão de EdC nas empresas.

A ética foi compreendida como pressuposto para as empresas de EdC por representar a coerência com a proposta, além de ser a base dos bens relacionais que surgem nas empresas, construídos também com base nos valores dos empresários e na adesão dos stakeholders a essa dinâmica que, quando alcançada a reciprocidade, passa a caracterizar o clima organizacional.

A interpretação e a adequação feitas pelos empresários dos princípios da EdC às suas empresas consistem em recursos que constroem, caracterizam e constituem a gestão de EdC e são as bases fundamentais para as práticas cotidianas específicas de cada empresa, embora a identidade de empresas de EdC permaneça preservada pela cultura de comunhão que a caracteriza. Os empresários, portanto, influenciam diretamente a construção dos recursos constitutivos da gestão própria de EdC em suas empresas.

Na Teoria Axiológica de Comunhão, a fé do empresário é concebida tanto no sentido de intervenção divina quanto no de crença no próprio negócio, como uma atividade voltada à solidariedade, como motivação para a adesão à proposta da EdC e como elemento corroborador de sua manutenção na empresa. O papel do empresário é fundamental nesse processo, por ser a base da gestão de EdC, desde a iniciativa em adotá-la até o empenho cotidiano em torná-la perene na empresa. 
Em síntese, a Teoria Axiológica de Comunhão, conforme sugere o próprio nome, tem como base dois elementos fundamentais que embasam a explicação da construção dos recursos que constituem a gestão de empresas de EdC: os valores dos empresários e a cultura de comunhão. Esses conceitos se relacionam com todos os demais recursos que constroem, caracterizam e constituem a gestão de empresas baseada na $\mathrm{EdC}$, mantendo entre si uma lógica de interdependência, conforme os próprios pressupostos construtivistas presumem.

No tocante à avaliação da teoria substantiva, foram adotados os critérios propostos por Bandeira-de-Mello e Cunha (2007): relevância, grau de coerência, integração, densidade, funcionalidade e flexibilidade, bem como o critério acrescentado por Maciel (2011): comparação com a literatura. As técnicas usadas para atingir esses critérios foram as sugeridas pelos mesmos autores somadas às de Strauss e Corbin (2008): a verificação com os sujeitos, a fim de que me informassem se a teoria se ajustava a seus casos; a verificação das proposições geradas na busca de casos afirmativos e negativos, o que também contou com a validação de alguns entrevistados; a amostragem em diferentes contextos - a pesquisa foi conduzida em empresas de diferentes portes, setores, tempo de existência e de adesão à EdC - e triangulação, ou seja, o uso de múltiplas fontes de dados - as fontes de dados da pesquisa foram as entrevistas e os documentos da EdC.

A Teoria Axiológica de Comunhão atende ao critério de relevância, que pressupõe que "a teoria deve emergir e ser fruto da sensibilidade teórica do pesquisador, que deve ser capaz de identificar a categoria central mais relevante para explicar o fenômeno" (BANDEIRA-DE-MELLO e CUNHA, 2007, p. 256). Também atendeu ao critério grau de coerência segundo o qual "as categorias da teoria devem ser inferidas dos dados" (BANDEIRA-DE-MELLO e CUNHA, 2007, p. 256) e devem permitir a compreensão da realidade dos indivíduos. A teoria emergiu dessa sensibilidade teórica e dos dados e a categoria central identificada foi a influência axiológica, confirmada por meio das técnicas citadas.

A integração da teoria é o critério pelo qual "todos os constructos devem estar relacionados em torno de uma categoria central e expressos em termos de proposições derivadas de um esquema teórico" (BANDEIRA-DE-MELLO e CUNHA, 2007, p. 256). Todas as proposições da Teoria Axiológica de Comunhão apresentaram relação com a categoria central (influência axiológica), o que resultou na lógica explicativa da teoria.

Densidade é o critério que prevê que "a teoria deve possuir poucas categorias-chave e um grande número de propriedades e categorias relacionadas" (BANDEIRA-DE-MELLO e CUNHA, 2007, p. 256). Segundo o trabalho de Maciel (2011), os autores se referem ao número de categorias e de códigos que as compõem para definir densidade. A Teoria Axiológica de Comunhão foi formada por sete categorias-chave, um número pequeno, com 92 códigos, tendo assim atendido ao critério de densidade, que "confere confiabilidade aos constructos da teoria" (BANDEIRA-DE-MELLO e CUNHA, 2007, p. 256).

O critério da funcionalidade pressupõe que a teoria seja "útil para os envolvidos" (BANDEIRA-DE-MELLO e CUNHA, 2007, p. 256), o que consistiu em uma das justificativas desta pesquisa e naquilo que se esperava com a construção de uma Grounded Theory: esclarecer aos empresários seu papel na construção social dos recursos que constituem a gestão de empresas baseada na EdC, o que pode auxiliá-los no próprio direcionamento dessa gestão. A Teoria Axiológica de Comunhão atingiu esse objetivo.

O critério da flexibilidade, por sua vez, pressupõe que "a teoria deve ser passível de modificação, permitindo que novos casos a enriqueçam com a introdução de novas propriedades e categorias. Uma teoria substantiva deve ser aberta para o aprimoramento de seu poder explicativo" (BANDEIRA-DE-MELLO e CUNHA, 2007, p. 256). A Teoria Axiológica de Comunhão tem essa abertura e permite ampliação e aprimoramento por meio de novas pesquisas.

Outro critério para a avaliação da teoria substantiva foi o acrescentado por Maciel (2011): o de comparação com a literatura. A Resource-Based View consistiu em importante fonte de sensibilização teórica para a construção da teoria substantiva, tendo sido consideradas suas contribuições e limitações. Embora a RBV em algumas de suas vertentes - como a proposta por Mills, Platts, Bourne et al. (2002), por exemplo - possa dialogar com a Teoria Axiológica de Comunhão, isso pode ocorrer somente até o ponto em que seus pressupostos epistemológicos distintos não entrem em contradição.

É importante salientar que a Teoria Axiológica de Comunhão tem como característica constituinte aquilo que na RBV é considerada uma limitação: a ambiguidade causal. Isso se dá porque o processo de construção social dos recursos que constituem a abordagem de gestão de EdC é um movimento contínuo de sobreposição e interdependência do papel do empresário e dos próprios recursos construídos socialmente. Portanto, essa teoria substantiva tem na ambiguidade causal não um limite, mas uma característica distintiva e constituinte. 


\section{CONSIDERAÇÕES FINAIS}

Nessa pesquisa foi desenvolvida uma teoria substantiva para a área substantiva formada pelas empresas de Economia de Comunhão. Por sua natureza distinta, sobretudo no que concerne ao aspecto relacionado à gestão, essa área não pôde ser satisfatoriamente explicada pelas teorias da estratégia e do management como se encontram até o momento, justificando a geração de uma Grounded Theory.

A teoria substantiva decorrente de todo o processo apresentado foi chamada de Teoria Axiológica de Comunhão e assume os seguintes pressupostos ontológicos e epistemológicos: a realidade é vista como uma esfera de discurso simbólico (MORGAN e SMIRCICH, 1980) e socialmente construída (BERGER e LUCKMANN, 2009). O paradigma adotado como meio para a compreensão da realidade foi o interpretativista, que pressupõe que o conhecimento pode ser criado ou compreendido só do ponto de vista dos indivíduos que fazem parte do ambiente estudado (HATCH, 1997).

O conceito de recurso foi revisitado para compor a Teoria Axiológica de Comunhão e adaptar-se à área substantiva. Esse conceito decorreu do processo de sensibilização teórica tanto com relação aos conceitos propostos na RBV quanto de Smircich (1983) sobre cultura e teve como base a epistemologia construtivista e a perspectiva interacionista simbólica, resultando no seguinte conceito: recursos são os elementos que - por meio de seu conjunto de serviços - constroem, caracterizam e constituem a gestão de empresas baseada na Economia de Comunhão. De modo amplo, foram considerados recursos para a gestão de Economia de Comunhão a influência axiológica, a cultura de comunhão, os hábitos e costumes voltados à gestão de $E d C$, os bens relacionais, o empirismo e a adequação, a ética e a fé.

Por meio de suas proposições, a Teoria Axiológica de Comunhão explica que a influência axiológica dos empresários e a cultura de comunhão são os elementos determinantes para a construção social dos recursos que constituem a gestão de empresas baseada na EdC. Os empresários desempenham, então, o papel daquele que interpreta, age e promove a interação tanto entre os próprios recursos - que, por vezes, quando combinados, geram outros recursos - quanto entre os stakeholders para construir e manter a gestão de EdC em suas empresas. São eles que motivam e articulam recursos e pessoas, originando uma abordagem própria de gestão de EdC.

Apesar de específica em cada empresa, a gestão de empresas baseada na EdC tem como elemento unificador a cultura de comunhão, oriunda dos princípios do Movimento dos Focolares, que mantém a identidade comum entre as empresas de EdC, não obstante o processo de construção social dos recursos que é distinta em cada uma delas.

Os hábitos e os costumes relacionados à gestão de EdC são construídos por influência axiológica dos empresários e pela resposta dos funcionários a esses valores. O exemplo do empresário é fundamental nesse processo. A ética é recurso que permeia a gestão de EdC e uma das bases fundamentais para construir bens relacionais. Quando os stakeholders se inserem nesse processo, há uma dinâmica de reciprocidade que passa a caracterizar o clima organizacional, bem como os relacionamentos externos.

A fé também é recurso para a gestão de EdC, tanto no sentido da percepção da intervenção divina quanto no da crença na missão da empresa como espaço para a vivência da solidariedade e essa fé é, primeiro, a do empresário. É ele quem toma a decisão de aderir à EdC e de interpretar seus princípios por meio de seus valores, a fim de construir em suas empresas a gestão de EdC.

Os recursos nas empresas de EdC são interdependentes. Essa natureza dos recursos faz que haja ambiguidade causal no que se refere à relação entre eles e à gestão de EdC. Todavia, na Teoria Axiológica de Comunhão, a ambiguidade causal é uma característica, coerente com seus pressupostos epistemológicos - e não uma limitação conforme é concebida na RBV.

Por fim, embora esse tipo de organização $(E d C)$ assuma valores éticos e religiosos específicos, seu estudo é relevante, dado que espelha a complexidade e a heterogeneidade do campo administrativo que comporta formas de gestão diversas.

Como recomendações para futuras pesquisas, propõe-se a criação de outras teorias substantivas para a mesma área, considerando outros aspectos da gestão, a fim de se criar ao longo do tempo o esboço de uma teoria formal para a área substantiva. Além disso, recomenda-se a aplicação dessa teoria em outras empresas de Economia de Comunhão, localizadas em diferentes países, para se avaliar sua aplicabilidade em contextos distintos. 


\section{REFERÊNCIAS}

ACEDO, F. J.; BARROSO, C.; GALAN, J. L. The Resource-Based Theory: dissemination and main trends. Strategic Management Journal, v. 27, p. 621-636, 2006.

AMIT, R.; SCHOEMAKER, P. Strategic assets and organizational rent. Strategic Management Journal, v. 14, p. 33-46, 1993.

BANDEIRA-DE-MELLO, R.; CUNHA, C. J. C. A. Grounded Theory. In: GODOI, C. K.; BANDEIRA-DE-MELLO, R.; SILVA, A. B. (Org.). Pesquisa qualitativa em estudos organizacionais: paradigmas, estratégias e métodos. São Paulo: Saraiva, 2007. 241-266 p.

BARNEY, J. B. Organizational culture: can it be a source of sustained competitive advantage? Academy of Management Review, v. 11, n. 3, p. 656-665, 1986.

BARNEY, J. B. Firm resources and sustained competitive advantage. Journal of Management, v. 17, n. 1, p. 99-120, 1991.

BARNEY, J. B.; KETCHEN JR., D. J.; WRIGHT, M. The future of ResourceBased Theory: revitalization or decline? Journal of Management, v. 37, n. 5, p. 1299-1315, 2011.

BERGER, P. L.; LUCKMANN, T. A construção social da realidade. 31. ed. Petrópolis, RJ: Vozes, 2009.

BRUNI, L. Mensagem de fim de ano aos empresários das empresas de EdC. 2012. Disponível em: <http://www.edc-online.org/ br/home/noticias/2865-e-natale.html>. Acesso em: 27 dez. 2012.

BRYSON, J. M.; ACKERMANN, F.; EDEN, C. Putting the ResourceBased View and distinctive competencies to work in public organizations. Public Administration Review, v. 67, p. 702-717, 2007.

BURRELL, G.; MORGAN, G. Sociological paradigms and organisational analysis. London: Heinemann Education Books, 1979.

CARTEIRA de identidade da economia de comunhão. Disponível em: <http://www.edc-online.org/br/empresas/a-carteira-de-identidade-da-edc.html>. Acesso em: 12 mar. 2012.

CAVES, R. E. Industrial organization, corporate strategy and structure. Journal of Economic Literature, v. 18, p. 64-92, 1980.

CHARMAZ, K. A construção da teoria fundamentada: guia prático para análise qualitativa. Porto Alegre: Artmed, 2009.

CLARKE, A. E. Situational analysis: Grounded Theory after the postmodern turn. London: Sage, 2005.

COLLINS, D. J.; MONTGOMERY, C. A. Competing on resources: strategy in the 1990s. Harvard Business Review, v. 73, n. 4, p. 118-128, 1995.

CONNER, K. R. A historical comparison of Resource-Based View and five schools of thought within industrial organization economics: do we have a new theory of the firm? Journal of management, $v$. 17, n. 1, p. 121-154, 1991.

CRIVELLI, L. Le imprese e gli imprenditori EdC nel mondo. Economia di Comunione-Rapporto 2010/2011. 2011. Disponível em: <http:// www.edc-online.org/br/publicacoes/documentos-pdf/search_ result.html>. Acesso em: 15 jul. 2012.
DEMSETZ, H. Industry structure, market rivalry, and public policy. Journal of Law and Economics, v. 16, p. 1-9, 1973.

DIERICKS, I.; COOL, K. Asset stock accumulation and sustainability of competitive advantage. Management Science, v. 35, n. 12, p. 1504-1513, 1989.

ESTATUTOS gerais da obra de Maria. Vargem Grande Paulista, SP: Cidade Nova, 2007.

FOSS, N. J. Resources and strategy: a brief overview of themes and contributions. In: FOSS, N. J. (Org.). Resources firms and strategies. New York: Oxford University Press, 1997. 3-18 p.

GLASER, B. G.; STRAUSS, A. L. The discovery of grounded theory: strategies for qualitative research. Piscataway, NJ: Aldine Transaction, 1967.

GRANT, R. M. The Resource-Based Theory of competitive advantage: implications for strategy formulation. California Management Review, v. 33, n. 3, p. 114-135, 1991.

GUI, B. Teoria economica e motivazioni ideali. In: CONGRESSO INTERNAZIONALE DI ECONOMIA, 2001, Castelgandolfo, Proceedings... Castelgandolfo: $\mathrm{CIE}, 2001$.

$\mathrm{HATCH}, \mathrm{M}$. J. Organization theory: modern, symbolic and postmodern perspectives. New York: Oxford University Press, 1997.

JOHNSON, G.; WHITTINGTON, R.; SCHOLES, K. Exploring strategy. Text and cases, Financial Times. 9. ed. London: Prentice Hall, 2011.

LINHAS para gestão de uma empresa de EDC. 2007. Disponível em: <http://www.edc-online.org/it/pubblicazioni/documenti-pdf/ doc_view/357-linhas-para-gestao-de-uma-empresa-de-edc.html>. Acesso em: 12 mar. 2012.

LIPPMAN, S.; RUMELT, R. Uncertain imitability: an analysis of interfirm differences in fficiency under competition. Bell Journal of Economics, v. 13, p. 418-438, 1982.

LUBICH, C. A experiência Economia de Comunhão: da espiritualidade da unidade, uma proposta de agir econômico. In: BRUNI, L. (Org.). Economia de Comunhão: uma cultura econômica em várias dimensões. Vargem Grande Paulista, SP: Cidade Nova, 2002. 13-19 p.

MACIEL, C. O. Teoria da dotação social estratégica: uma explicação sobre a construção social de estratégias e seus praticantes em setores emergentes da internet. 183f. Tese (Doutorado em Administração) - Pontifícia Universidade Católica do Paraná, Curitiba, 2011.

MANCKE, R. Causes of interfirm profitability differences: a new interpretation of the evidence. Quarterly Journal of Economics, v. 88, n. 2, p. 181-193, 1974.

MILLS, J. et al. Competing through competences. Cambridge: Cambridge University Press, 2002.

MONTGOMERY, C. A. Of diamonds and rust: a new look at resources. In: MONTGOMERY, C. A. (Org.). Resource-Based and evolutionary theories of the firm: towards a synthesis. Norwell: Kluwer Academic Publishers, 1995. 251-268 p. 
MORGAN, G.; SMIRCICH, L. The case for qualitative research. Academy of Management Review, v. 5, n. 1, p. 491-500, 1980.

PENROSE, E. The theory of the growth of the firm. New York: Oxford University Press, 1959.

PINHEIRO, M. B. (Org.). Documento do movimento econômico de comunhão. In: ECONOMIA DE COMUNHÃO E MOVIMENTO ECONÔMICO: DESENVOLVIMENTO E PERSPECTIVAS, 2., 1999, Vargem Grande Paulista. Anais... Vargem Grande Paulista, SP: Cidade Nova, 2000. p. 165-168. Disponível em: <http://www.edc-online. org/br/testi-pdf/anais-edc_99_02.pdf>. Acesso em: 21 nov. 2005.

PORTER, M. E. Towards a dynamic theory of strategy. Strategic Management Journal, v. 12, p. 95-117, 1991.

PRIEM, R. L.; BUTLER, J. E. Is the Resource-Based "View" a useful perspective for strategic management research? Academy of Management Review, v. 26, n. 1, p. 22-40, 2001a.

PRIEM, R. L.; BUTLER, J. E. Tautology in the Resource-Based View and the implications of externally determined resource value: further comments. Academy of Management Review, v. 26, n. 1, p. 57-66, 2001b.

QUEM SOMOS. Disponível em: <http://focolares.org.br/sitenacional/ movimento-dosfocolares/quem-somos/>. Acesso em: 15 jul. 2012.

REED, R.; DEFILLIPPI, R. Causal ambiguity, barriers to imitation, and sustainable competitive advantage. Academy of Management Review, v. 15, n. 1, p. 88-102, 1990.

RUBIN, P. H. The expansion of firms. Journal of Political Economy, v. 81, n. 4, p. 936-949, 1973.
RUMELT, R. Inertia and transformation. In: MONTGOMERY, C. A. (Org.). Resource-Based and evolutionary theories of the firm: towards a synthesis. Norwell: Kluwer Academic Publishers, 1995. 101-132 p.

SMIRCICH, L. Concepts of culture and organizational analysis. Administrative Science Quarterly, v. 28, n. 3, p. 339-358, 1983.

STATEMENT submitted by New Humanity, a non-governmental organization in consultative status with the Economic and Social Council. 2012. Disponível em: <http://daccess-dds-ny.un.org/doc/ UNDOC/GEN/N11/598/19/PDF/N1159819.pdf?OpenElement>. Acesso em: 13 dez. 2012.

STRAUSS, A. L. Qualitative analysis for social scientists. Cambridge: Cambridge University Press, 1987.

STRAUSS, A. L.; CORBIN, J. Pesquisa qualitativa: técnicas e procedimentos para o desenvolvimento de teoria fundamentada. 2. ed. Porto Alegre: Artmed, 2008.

TAROZZI, M. O que é a Grounded Theory: metodologia de pesquisa e de teoria fundamentada nos dados. Petrópolis, RJ: Vozes, 2011.

WELLS, K. The strategy of Grounded Theory: possibilities and problems. Social Work Research, v. 19, n. 1, p. 33-37, 1995.

WERNERFELT, B. A Resource-Based View of the firm. Strategic Management Journal, v. 5, n. 2, p. 171-180, 1984.

WERNERFELT, B. Resource-Based strategy in a stochastic model. In: MONTGOMERY, C. A. (Org.). Resource-Based and evolutionary theories of the firm: towards a synthesis. Norwell: Kluwer Academic Publishers, 1995. 133-145 p.

Cláudia Herrero Martins Menegassi

Doutora em Administração pela Universidade Positivo (UP); Professora do Programa de Pós-Graduação em Gestão do Conhecimento nas Organizações (PPGGCO) na Unicesumar. E-mail: claudiaherrero@gmail.com

Bruno Henrique Rocha Fernandes

Doutor em Administração de Empresas pela Universidade de São Paulo (USP); Professor do Programa de Mestrado e Doutorado em Administração (PMDA) da Universidade Positivo (UP). E-mail: bruno@up.edu.br 